\title{
EKPERIMENTASI MODEL PEMBELAJARAN DISCOVERY DAN GROUP INVESTIGATION TERHADAP PRESTASI BELAJAR MATEMATIKA DITINJAU DARI KREATIVITAS SISWA
}

\author{
Ira Vahlia \\ FKIP Universitas Muhammadiyah Metro \\ E-mail : iravahlia768@yahoo.co.id
}

\begin{abstract}
The aim of the research was to determine the effect of learning models on mathematics achievement viewed from the student creativity. The learning model compared were discovery, group investigation and conventional. The type of the research was a quasi-experimental research. The population was the students of Junior High Schoolin Surakarta city on academic year 2012/2013. The samples of this research were taken by using the stratified cluster random sampling technique. The samples consist of 281 students who were divided into 94 students in the first experiment class, 94 students in the second experiment class, and 93 students in the control class. The results of this research are as follows: (1) the discovery learning model results in better learning achievement than the group investigation and conventional learning model. The group investigation learning model results in an equal learning achievement to the conventional learning model, (2) the students having high level of creativity have better learning achievement than those having medium and low levels of creativity. The students having medium level of creativity have an equal learning achievement to those having low level of creativity, (3) on the discovery learning model, students having high creativity have better learning achievement than those having medium and low levels of creativity and students having medium level of creativity have an equal learning achievement to those having low creativity. On the group investigation model, students in each level of creativity have the same learning achievement, (4) the students who were tought with the discovery learning model have better learning achievement than those taught with the group investigation and conventional learning model in the category of having high level of creativity. The students who were tought group investigation and conventional model results in an equal learning achievement in the category of having high level of creativity. The students having medium level of creativity have an equal learning achievement to those having low level of creativity in each learning model.
\end{abstract}

Keywords :Discovery, group investigation, learning achievement, and creativity.

Aksioma

Jurnal Pendidikan Matematika FKIP Univ. Muhammadiyah Metro 


\section{PENDAHULUAN}

Pendidikan memerlukan inovasi yang sesuai dengan kemajuan ilmu pengetahuan dan teknologi tanpa mengabaikan nilai-nilai kemanusiaan. Berbagai upaya telah dilakukan pemerintah untuk melakukan inovasi dalam dunia pendidikan, misalnya dengan memperkenalkan berbagai model pembelajaran inovatif. Berkenaan dengan daya serap siswa, dapat dilihat pada daya serap siswa SMP Kota Surakarta terhadap penguasaan materi soal matematika ujian nasional, salah satunya pada kemampuan dalam menentukan penyelesaian sistem persamaan linear dua variabel. Berdasarkan data daya serap Puspendik Kemdiknas 2011, dapat dilihat bahwa pada kompetensi yang diuji untuk tingkat Kota hanya $52.77 \%$ siswa yang menjawab benar dan $53.57 \%$ untuk tingkat provinsi, sedangkan persentase dari tingkat nasional mencapai $72.00 \%$. Hal ini menandakan bahwa daya serap pada kompetensi menentukan penyelesaian sistem persamaan linear dua variabel di tingkat Kota Surakarta lebih rendah daripada tingkat Propinsi dan nasional.

$$
\text { Masalah klasik dalam }
$$

pendidikan matematika yaitu rendahnya prestasi belajar matematika siswa. Proses pembelajaran yang terjadi satu arah, yang hanya menekankan pada aspek kognitif siswa saja, sedangkan aspek afektif dan aspek psikomotor siswa kurang diperhatikan. Siswa hanya "mengetahui" dan tidak "mengalami" apa yang dipelajarinya. Prestasi belajar matematika dipengaruhi beberapa faktor, dua diantaranya adalah kreativitas siswa dan model pembelajaran guru. Beberapa model pembelajaran interaktif diharapkan mampu mengatasi permasalahan dalam pembelajaran matematika. Model pembelajaran yang banyak digunakan di sekolah yang sudah maju diantaranya discovery dan group Investigation sehingga dapat mengembangkan kreativitas siswa.

Model pembelajaran discovery merupakan suatu cara untuk mengembangkan belajar siswa aktif dengan menemukan sendiri, menyelidiki sendiri, maka hasil yang akan diperoleh akan tahan lama dalam ingatan, tidak mudah dilupakan siswa. Sedangkan pada model group investigation terdapat proses berpikir berdasarkan pertanyaan yang muncul dari permasalahan, sehingga model ini dapat meningkatkan penguasaan akademis siswa, memberikan waktu kepada siswa untuk berpikir serta saling membantu satu sama lain.Di dalam pembelajaran matematika di kelas tidak hanya dipengaruhi oleh model mengajar saja, namun tingkat kreativitas juga diduga mempengaruhi prestasi belajar siswa. Dalam Abu Ahmadi (2004: 97) 
berpendapat, "Dalam kegiatan belajar anak golongan kreatif lebihmampu menemukan masalah dan mampu memecahkan masalah". Secara universal anak mempunyai tingkat kreativitas yang berbeda-beda, ada yang sudah mempunyai tingkat kreativitas yang tinggi namun ada juga yang masih rendah. Kreativitas siswa mempunyai pengaruh yang cukup besar dalam mengoptimalkan prestasi belajar siswa.

Menurut Shriki (2009: 162) penilaian kreativitas berkaitan dengan evaluasi diri. Penting bahwa guru harus memiliki kreativitas matematika agar dapat menilai kreativitas siswanya, hal yang tidak kalah penting bahwa guru mengembangkan kemampuan siswa untuk meningkatkan kreativitas siswanya. Guru dapat mendiskusikan dengan masalah siswa yang menyangkut evaluasi pemikiran mereka serta proses itu sendiri. Evaluasi diri tersebut memungkinkan siswa untuk mengatasi persoalan.

Dengan model discovery dan group investigation diperkirakan mampu mendukung peningkatan kreativitas siswa yaitu mengembangkan kemampuan siswa dalam berpikir secara kritis dan kreatif. Dalam model pembelajaran ini siswa menemukan dan mengkonstruksi sendiri sehinggaakan mendorong siswa berkreativitas menemukan konsep-konsep atau ide-ide baru dalam matematika yang belum pernah diketahui sebelumnya. Selain itu juga memberikan kesempatan yang seluas-luasnya kepada siswa untuk dapat menggunakan kemampuan bernalarnya dan membiasakan untuk senantiasa berpikir kreatif. Konsepkonsep yang didapat oleh siswa dari hasil penemuannya sendiri akan lebih bermakna dan pemahaman siswa terhadap konsep tersebut akan meningkat. Oleh karena itu sudah seharusnya guru menempatkan kreativitas sebagai salah satu tujuan pembelajaran.

Penelitian ini mempunyai tujuan untuk mengetahui: (1) manakah yang memberikan prestasi belajar matematika lebih baik, model pembelajaran discovery, model group investigation atau konvensional. (2) manakah yang mempunyai prestasi belajar matematika lebih baik, siswa dengan kreativitas tinggi, sedang atau rendah. (3) manakah yang memberikan prestasi belajar matematika lebih baik pada kategori kreativitas tinggi, sedang atau rendah pada masing-masing model pembelajaran. (4) manakah yang memberikan prestasi belajar matematika lebih baik, model pembelajaran discovery, group investigation atau konvensional pada masing-masing tingkat kategori kreativitas siswa.

\section{METODE PENELITIAN}

\begin{tabular}{crlr}
\multicolumn{2}{c}{ Penelitian } & ini & dilaksanakan \\
diSMP & Negeri & SeKota & Surakarta
\end{tabular} 
ProvinsiJawa pada semester ganjil tahun pelajaran2012/2013. Jenis penelitianini adalahpenelitian eksperimental semu (quasi experimental research). Populasi dalam penelitian ini adalah siswa SMP Kelas VIII semester ganjil tahun pelajaran 2012/2013. Populasi ini tersebar di 27 SMP Negeri yang ada di Kota Surakarta. Sampling dalam penelitian ini menggunakan teknik stratified cluster random sampling sehingga terpilih sampel sebagai kelompok tinggi yaitu siswa SMP Negeri 8 Surakarta,kelompok sedang yaitu siswa SMP Negeri 14 Surakarta, dan kelompok rendah yaitu siswa SMP Negeri 21 Surakarta.

Metode pengumpulan data penelitian meliputi metode dokumentasi, tes, dan angket. Metode dokumentasi digunakan untuk memperoleh data mengenai jumlah dan daftar nama serta nilai Ujian Tengah Semester siswa yang menjadi sampel penelitian. Metode tes digunakan untuk memperoleh data prestasi belajar matematika siswa. Metode angket digunakan untuk memperoleh data kreativitas belajar siswa. Sebelum melakukan eksperimen, dilakukan uji keseimbangan terhadap kemampuan awal matematika menggunakan anava satu jalan dengan sel tak sama. Data prestasi belajar matematika dianalisis menggunakan analisis variansi dua jalan dengan sel tak sama. Sebelumnya, terhadap data kemampuan awal maupun data prestasi belajar dilakukan uji prasyarat meliputi uji normalitas populasi menggunakan metode Lilliefors dan uji homogenitas variansi populasi menggunakan metode Bartlett. Uji hipotesis menggunakan analisis variansi dua jalan dengan sel taksama. Apabilahasil analisis variansi menunjukkan bahwa hipotesis nol ditolak, dilakukan uji komparasi ganda menggunakan metode Scheffe'. (Budiyono, 2009: 170-216).

\section{HASIL PENELITIAN DAN PEMBAHASAN}

Hasil uji prasyarat menyimpulkan bahwa semua sampel berasal dari populasi yang berdistribusi normal dan populasi-populasi yang mempunyai variansi yang sama (homogen). Hasiluji keseimbangan diperoleh simpulan bahwa populasi mempunyai kemampuan awal matematika yang seimbang. Pengujian hipotesis juga melibatkan interaksi antar masing-masing model pembelajaran dan kreativitas. Deskripsi data hasil penelitian di sajikan pada Tabel 1 berikut: 
Tabel 1. Deskripsi Data Prestasi belajar Matematika Siswa pada Masing-Masing Kategori Model pembelajaran dan Kreativitas

\begin{tabular}{|c|c|c|c|c|}
\hline \multicolumn{2}{|c|}{ Model Pembelajaran } & \multicolumn{3}{|c|}{ Kreativitas } \\
\hline & & Tinggi & Sedang & Rendah \\
\hline \multirow{5}{*}{ Discovery } & $N$ & 46 & 27 & 21 \\
\hline & Nilai Min & 40 & 36 & 32 \\
\hline & Nilai Max & 100 & 84 & 7615,25 \\
\hline & & 82,52 & 59,70 & 51,62 \\
\hline & & 13,68 & 16,87 & 15,25 \\
\hline \multirow{5}{*}{$\begin{array}{c}\text { Group } \\
\text { Investigation }\end{array}$} & $N$ & 34 & 33 & 27 \\
\hline & Nilai Min & 40 & 36 & 32 \\
\hline & Nilai Max & 96 & 84 & 76 \\
\hline & & 62,82 & 58,06 & 52,74 \\
\hline & & 17,71 & 17,44 & 19,03 \\
\hline \multirow{5}{*}{ Konvensional } & $N$ & 23 & 26 & 44 \\
\hline & Nilai Min & 36 & 36 & 32 \\
\hline & Nilai Max & 80 & 88 & 80 \\
\hline & & 54,09 & 54,62 & 49,45 \\
\hline & & 12,96 & 17,79 & 16,32 \\
\hline
\end{tabular}

Dengan taraf signifikansi 0,05, rangkuman hasil perhitungan analisis variansi dua jalan dengan sel tak sama disajikan dalam Tabel 2 berikut

Tabel 2. Rangkuman Analisis Variansi Dua Jalan dengan Sel Tak Sama Sumber Keputusan Uji

\begin{tabular}{|c|c|c|c|c|c|c|}
\hline Sumber & $J K$ & $d k$ & $R K$ & $F_{\text {obs }}$ & $F_{\alpha}$ & Keputusan Uji \\
\hline$A$ & 6243,0423 & 2 & 3121,5212 & 12,6723 & 3,0000 & Ho ditolak \\
\hline$B$ & 10257,8272 & 2 & 5128,9136 & 20,8216 & 3,0000 & Ho ditolak \\
\hline$A B$ & 6720,1709 & 4 & 1680,0427 & 6,8204 & 2,3700 & Ho ditolak \\
\hline$G$ & 67000,95 & 272 & 246,3270 & - & - & \\
\hline Total & 90221,9949 & 281 & - & - & - & \\
\hline
\end{tabular}

Berdasarkan tabel di atas, $H_{0 A}$ ditolak berarti model pembelajaran discovery, group investigation, dan konvensional memberikan efek yang berbeda terhadap prestasi pembelajaran. Hipotesis $H_{0 B}$ ditolak berarti kategori kreativitas tinggi, sedang, dan rendah memberikan efek yang berbeda 
terhadap belajar prestasi pembelajaran. Hipotesis $H_{0 A B}$ ditolak berarti terdapat interaksi antara model pembelajaran dan kategori kreativitas siswa terhadap prestasi pembelajaran.
Untuk hipotesis $H_{0}$ ditolak dilakukan uji komparasi ganda. Oleh karena $H_{0 A}$ ditolak, perlu dilakukan uji komparasi rerata antar baris.

Tabel 3. Rangkuman Hasil Uji Komparasi Rerata Antar Baris Pada Masing-Masing Model Pembelajaran

\begin{tabular}{|c|c|c|c|}
\hline$H_{0}$ & $F_{\text {hit }}$ & $F_{\text {tabel }}$ & Keputusan Uji \\
\hline$\mu_{1 .}=\mu_{2 .}$ & 22,2904 & 6,00 & $H_{0}$ ditolak \\
\hline$\mu_{1 .}=\mu_{3 .}$ & 54,9817 & 6,00 & $H_{0}$ ditolak \\
\hline$\mu_{2 .}=\mu_{3 .}$ & 7,3242 & 6,00 & $H_{0}$ ditolak \\
\hline
\end{tabular}

Hasil uji komparasi ganda menunjukkan bahwa prestasi belajar matematika siswa yang dikenai model pembelajaran discovery lebih baik daripada group investigation dan konvensional. Hal ini mungkin disebabkan karena pada pembelajaran group investigation belum menekankan agar siswa dapat menguasai materi yang diajarkan, melainkan lebih menekankan pada pemahaman mereka. Siswa diminta untuk mengambil kesimpulan dari suatu persoalan yang telah dibahas sebagai bahan pengkajian, analisis dan prosedur. Dengan jalan ini, mereka akan mencoba berpikir solutif dan inovatif sehingga pada akhirnya mereka mampu mengambil kesimpulan dan jawaban yang benar-benar valid mengenai suatu persoalan. Pembelajaran discovery menitikberatkan pada penguasaan mendalam tentang materi dan penyelesaian soal serta siswa dapat menemukan konsep materi yang dipelajari, sehingga dalam kegiatan pembelajaran siswa diberi kesempatan dan peluang yang banyak untuk bereksplorasi dalam situasi pembelajaran. Berbeda halnya dengan group investigation dan konvensional yang tidak diharuskan dalam menemukan konsep materi yang dipelajari. Hasil dari pengamatan di lapangan dimungkinkan kurang siapnya siswa dengan pembelajaran group investigation dan konvensional. Siswa kadang masih bingung terhadap apa yang ditanyakan. Herdian (2010) dimana hasil penelitian menunjukkan bahwa model discovery lebih baik daripada pembelajaran konvensional dalam kemampuan pembelajaran matematika siswa.

Prestasi belajar matematika siswa yang dikenai pembelajaran group investigation lebih baik dari 
prestasi belajar matematika siswa yang dikenai pembelajaran konvensional. Hal ini dimungkinkan karena siswa memilih topik yang ingin dipelajari, mengikuti investigasi mendalam terhadap berbagai subtopik yang telah dipilih, kemudian menyiapkan dan menyajikan persentasi ke depan kelas secara keseluruhan. Berbeda halnya dengan pembelajaran konvensional dimana siswa akan menerima konsep itu dari guru. Shlomo, et al (2007: 142-154) di dalam penelitian yang dilakukan terhadap kelas 7 (umur 13-14) di Singapura, efek dari model group investigation dari pembelajaran kooperatif lebih efektif dari efek dari model tradisional. Oleh karena $H_{0 B}$ ditolak, perlu dilakukan uji komparasi rerata antar kolom.

Tabel 4. Rangkuman Hasil Komparasi Antar Kolom

\begin{tabular}{|c|c|c|c|}
\hline$H_{0}$ & $F_{\text {hit }}$ & $F_{\text {tabel }}$ & Keputusan Uji \\
\hline$\mu_{\cdot 1}=\mu_{\cdot 2}$ & 28,0184 & 6,00 & $H_{0}$ ditolak \\
\hline$\mu_{\cdot 1}=\mu_{\cdot 3}$ & 69,4063 & 6,00 & $H_{0}$ ditolak \\
\hline$\mu_{\cdot 2}=\mu_{\cdot 3}$ & 7,9125 & 6,00 & $H_{0}$ ditolak \\
\hline
\end{tabular}

$H_{0 B}$ ditolak berarti dilakukan uji komparasi ganda. Hasil pengujian hipotesis menunjukkanbahwa prestasi belajar matematika siswa yang memiliki kreativitas tinggi lebih baik dibandingkan siswa yang memiliki kreativitas sedang dan rendah, dan prestasi belajar matematika siswa yang memiliki kreativitas sedang lebih baik dibandingkan siswa yang memiliki kreativitas rendah. Hasil penelitian ini sesuai dengan hipotesis penelitian yang menunjukkan bahwa prestasi belajar matematika siswa berbanding lurus dengan kreativitas siswa. Semakin tinggi kreativitas siswa, semakin baik pula prestasi belajar yang diperolehnya. Hai ini disebabkan karena dengan semakin tinggi kreativitas yang dimiliki siswa, maka memiliki berbagai macam kretivitas yang banyak terhadap sejumlah konsep tentang sistem persamaan linear dua variabel. Berdasarkan hasil angket kreativitas, siswa yang memiliki kreativitas tinggi memiliki kebiasaan dalam mencari berbagai referensi dari konsep maupun permasalahan dalam pembelajaran, bertanya pada guru matematika tentang kesulitan yang dialami, aktif mengikuti diskusi dengan teman dalam mengerjakan tugas matematika, dalam mempelajari materi matematika siswa tidak hanya menghapal namun memahaminya sehingga apabila diberikan permasalahan yang berbeda siswa dapat menyelesaikannya. Dengan demikian, semakin tinggi kreativitas, 
maka pemahaman siswa semakin optimal sehingga memperoleh prestasi belajar matematika yang optimal pula. Hasil ini sesuai dengan simpulan Siti Munjiyatun (2009) menunjukkan bahwa siswa yang kreativitasnya tinggi memiliki prestasi belajar yang lebih tinggi dibandingkan dengan siswa yang kreativitasnya sedang. Siswa yang kreativitasnya sedang memiliki prestasi belajar yang lebih tinggi dibandingkan dengan siswa yang kreativitasnya rendah.

Oleh karena $H_{0 A B}$ ditolak, perlu dilakukan uji komparasi rerata antar sel pada masing-masing kategori model pembelajaran dan kreativitas. Rangkuman hasil komparasi antar sel pada baris yang sama dapat dilihat pada Tabel 5 berikut:

Tabel 5. Rangkuman Hasil Komparasi Antar Sel pada Baris Yang Sama

\begin{tabular}{|c|c|c|c|}
\hline$H_{0}$ & $F_{\text {hit }}$ & $F_{\text {tabel }}$ & Keputusan Uji \\
\hline$\mu_{11}=\mu_{12}$ & 35,9619 & 15,52 & $H_{0}$ ditolak \\
$\mu_{11}=\mu_{13}$ & 55,8963 & 15,52 & $H_{0}$ ditolak \\
$\mu_{12}=\mu_{13}$ & 3,1344 & 15,52 & $H_{0}$ diterima \\
\hline$\mu_{21}=\mu_{22}$ & 1,5422 & 15,52 & $H_{0}$ diterima \\
$\mu_{21}=\mu_{23}$ & 1,7061 & 15,52 & $H_{0}$ diterima \\
$\mu_{22}=\mu_{23}$ & 6,2110 & 15,52 & $H_{0}$ diterima \\
\hline$\mu_{31}=\mu_{32}$ & 0,0138 & 15,52 & $H_{0}$ diterima \\
$\mu_{31}=\mu_{33}$ & 1,3159 & 15,52 & $H_{0}$ diterima \\
$\mu_{32}=\mu_{33}$ & 1,7671 & 15,52 & $H_{0}$ diterima \\
\hline
\end{tabular}

a. Pada siswa yang dikenai model pembelajaran discovery, prestasi belajar matematika siswa yang memiliki kreativitas tinggi lebih baik dibandingkan prestasi belajar matematika siswa yang memiliki kreativitas sedang maupun rendah. Prestasi belajar matematika siswa yang memiliki kreativitas sedang sama baiknya dengan siswa yang memiliki kreativitas rendah. Hal ini dimungkinkan karena pembentukan kelompok belajar pada pembelajaran discovery tidak memperhatikan heterogenitas kreativitas siswa. Dalam melaksanakan penelitian, data kreativitas siswa diukur pada pertemuan terakhir untuk pembalajaran ini. Dengan demikian, peneliti tidak mampu menjamin 
terjadinya interaksi belajar antara siswa yang memiliki kreativitas tinggi, sedang dan rendah. Astuti (2008) dimana hasil penelitiannya menyatakan bahwa model pembelajaran discovery dapat meningkatkan kreativitas siswa.

b. Pada siswa yang dikenai model pembelajaran group investigation dan konvensional, prestasi belajar matematika sama baiknya pada masing-masing kreativitas. Hal ini dimungkinkan karena penerapan model pembelajaran group investigation ini mampu mengakomodasi seluruh siswa dengan karakteristik kreativitas yang berbeda-beda dalam suatu kelompok untuk berdiskusi dalam menyelesaikan masalah. Pada pembelajaran konvensional hal ini dimungkinkan karena kreativitas siswa tidak terlihat dimana pembelajarannya berpusat pada guru. Dalam pelaksanaan penelitian, data kreativitas siswa diukur pada pertemuan terakhir.

Berdasarkan hasil komparasi rerata antar sel pada kolom yang sama pada masing-masing kategori model pembelajaran dan kreativitas, diperoleh simpulan bahwa:

Tabel 6. Rangkuman Hasil Komparasi Antar Sel pada Kolom yang Sama

\begin{tabular}{|c|c|c|c|}
\hline$H_{0}$ & $F_{\text {hit }}$ & $F_{\text {tabel }}$ & Keputusan Uji \\
\hline$\mu_{11}=\mu_{21}$ & 30,7956 & 15,52 & $H_{0}$ ditolak \\
$\mu_{21}=\mu_{31}$ & 4,2511 & 15,52 & $H_{0}$ diterima \\
$\mu_{11}=\mu_{31}$ & 50,3297 & 15,52 & $H_{0}$ ditolak \\
\hline$\mu_{12}=\mu_{22}$ & 0,1628 & 15,52 & $H_{0}$ diterima \\
$\mu_{22}=\mu_{32}$ & 0,7007 & 15,52 & $H_{0}$ diterima \\
$\mu_{12}=\mu_{32}$ & 1,3922 & 15,52 & $H_{0}$ diterima \\
\hline$\mu_{13}=\mu_{23}$ & 0,0603 & 15,52 & $H_{0}$ diterima \\
$\mu_{23}=\mu_{33}$ & 0,7336 & 15,52 & $H_{0}$ diterima \\
$\mu_{13}=\mu_{33}$ & 0,2704 & 15,52 & $H_{0}$ diterima \\
\hline
\end{tabular}

a. Pada siswa yang memiliki kreativitas tinggi, prestasi belajar matematika siswa yang dikenai model pembelajaran discovery lebih baik dari model pembelajaran group investigation dan konvensional. Sedangkan prestasi belajar matematika siswa yang dikenai model pembelajaran group investigation sama baiknya dengan 
pembelajaran konvensional. Hal ini tidak sesuai dengan hipotesis penelitian karena dalam pengisian angket kreativitas masih banyak siswa pada kelompok kontrol yang kurang jujur, sehingga berpengaruh pada pembagian kelompok siswa berdasarkan tingkat kreativitas siswa untuk kategori tinggi, sedang dan rendah. Bruner (dalam Suriadi, 2006: 5) menyatakan bahwa anak harus berperan aktif dan kreatif didalam belajar sehingga siswa yang memiliki kreativitas tinggi, prestasi belajar matematika siswa yang dikenai model pembelajaran discovery lebih baik dari siswa yang dikenai model pembelajaran group investigation dan konvensional

b. Pada siswa yang memiliki kreativitas sedang dan rendah, prestasi belajar matematika siswa yang dikenai model pembelajaran discovery, group investigation dan konvensional sama baiknya. Hal ini berbeda dengan hipotesis penelitian dikarenakan pada kreativitas sedang dan rendah, pada saat proses pembelajaran membutuhkan bimbingan yang lebih untuk dapat mengikuti proses pembelajaran akan tetapi proses pembimbingan tidak berjalan maksimal karena keterbatasan waktu. Hasil penelitian inisama dengan hasil penelitian Armin Hary (2011) dimana tidak terdapat perbedaan prestasi belajar siswa pada kreativitas sedang maupun rendah. Berdasarkan kondisi di lapangan, siswa masih bingung dan kesulitan dalam menjawab pertanyaan yang ada pada angket.

\section{KESIMPULAN DAN SARAN}

Berdasarkan hasil penelitian, dapat disimpulkan sebagai berikut:

1. Prestasi belajar matematika siswa yang dikenai model pembelajaran discovery lebih baik dari model pembelajaran group investigation dan konvensional. Prestasi belajar matematika siswayang dikenai model pembelajaran group investigation sama baiknya dengan pembelajaran konvensional.

2. Prestasi belajar matematika siswa yang memiliki kreativitas tinggi lebih baik dibandingkan kreativitas sedang maupun rendah. Prestasi belajar matematika siswa yang memiliki kreativitas sedang lebih baik dari kategori kreativitas rendah.

3. Pada siswa yang dikenai model pembelajaran discovery, prestasi belajar matematika siswa yang memiliki kreativitas tinggi lebih baik dibandingkan siswa yang memiliki kreativitas sedang maupun rendah, dan prestasi belajar matematika siswa yang memiliki kreativitas sedang sama baiknya dengan siswa yang memiliki kreativitas rendah. Pada 
siswa yang dikenai model pembelajaran group investigation dan konvensional, prestasi belajar matematika sama baiknya untuk masing-masing kategori kreativitas.

4. Pada siswa yang memiliki kreativitas tinggi, prestasi belajar matematika siswa yang dikenai model pembelajaran discovery lebih baik dibandingkan model pembelajaran group investigation dan konvensional, dan prestasi belajar matematika siswa yang dikenai model pembelajaran group investigation sama baiknya dengan siswa yang dikenai pembelajaran konvensional. Pada siswa yang memiliki kreativitas sedang dan rendah, prestasi belajar matematika sama baiknya untuk masingmasing model pembelajaran.

Dari kesimpulan di atas, diharapkan bagi guru memilih model yang tepat dalam pembelajaran. Di antaranya model pembelajaran discovery yang mampu membuat siswa mengkontruksi pengetahuannya sendiri sehingga dapat digunakan untuk memecahkan masalah dalam kehidupan. Selain itu bagi peneliti lain dapat digunakan sebagai acuan atau dapat dipakai sebagai salah satu referensi untuk melakukan penelitian yang lain. Diharapkan para peneliti dapat mengembangkan penelitian untuk variabel atau model pembelajaran lain yang sejenis sehingga dapat menambah kualitas pendidikan yang lebih baik.

\section{DAFTAR PUSTAKA}

Abu Ahmadi dan Widodo Supriyono. 2004. Psikologi Belajar. Jakarta: Rineka Cipta.

Armin Hary. Pembelajaran 2011. Efektifitas Menggunakan Quantum Learning dan Pendekatan Contextual Teaching and Learning pada Pokok Bahasan Statistika ditinjau dari Kreativitas Belajar Peserta Didik SMA di Kota Palangkaraya. Tesis S2. Tidak dipublikasikan. Program Pascasarjana UNS. Surakarta.

Astuti, D. 2008. Pengaruh Implementasi Model Discovery dalam Pembelajaran Matematika Terhadap Kemampuan Berpikir Kreatif Siswa Kelas VIII SMP Negeri I Bandung. Tesis S2. Tidak dipublikasikan.

Program Pascasarjana UPI. Bandung.

Budiyono. 2009. Statistika Dasar untuk Penelitian Edisi ke-2. Surakarta: UNS Press.

Herdian. 2010. Pengaruh Model Discovery Terhadap Kemampuan Analogi dan Generalisasi Matematis Siswa SMP. Tesis S2. Tidak dipublikasikan. Program Pascasarjana UNS. Surakarta.

Shlomo, S. \& Tan, I.G.C. 2007. Group Investigation effects on achievment, motivation and perpections of students in Singapore. SingaporeJournal of Educational Studies in Mathematics. 73 (4): 142-154. 
Diunduh dari http://heldref.orgpada 13 Februari 2012 pukul 10.35 WIB.

Shriki, A. 2009. Working like real mathematicians: developing prospective teachers' awareness of mathematical creativity through generating new concepts. New YorkJournal of Educational Studies in Mathematics. 73 (2): 162.Diunduh dari http://www.springer.com/research pada 13 Februari 2012 pukul 15.30 WIB.

Siti Munjiyatun. 2009. Pengaruh Model Pembelajaran Kooperatif Tipe Student Teams Achievements Division (STAD) dan Tipe Student Teams Achievement Division (STAD) dan Tipe Group Investigation (GI) Terhadap Prestasi Belajar Matematika Ditinjau Dari Siswa. Tesis S2. Tidak dipublikasikan. Program Pascasarjana UNS. Surakarta.

Suriadi. 2006. Pembelajaran dengan Pendekatan Discovery yang Menekankan Aspek Analogi Untuk Menigkatkan Pemahaman Matematik dan Kemampuan Berfikir Kritis Siswa SMA. Tesis S2. Tidak dipublikasikan. Program Pascasarjana UPI. Bandung. 
ISSN 2442-5419 Vol. 3, No. 2 (2014) 43-54 